\title{
AÇÃO INIBIDORA DE TERMOFOSFATO MAGNESIANO SOBRE A FECUNDIDADE DE PLANOBIDEOS E SEU POSSIVEL SIGNIFICADO NO CONTROLE DA ESQUISTOSSOMOSE MANSONI *
}

Roberto Milward-de-Andrade ** Leonardo Fittipaldi Torga***

MILWARD-DE-ANDRADE, R. \& TORGA, L. F. Acào inibidora de termofosfato mag-
nesiano sobre a fecundidade de planorbideos e seu possivel significado no
controle da esquistossomos: mansoni. Rev. Saude públ., S. Paulo, 15:59-71, 1981.

RESUMO: A eficácia de termofosfato magnesiano (fertilizante e corretivo do solo) na alimentação de planorbídeos, em laboratório, foi testada ao longo de cinco semanas, verificando-se o crescimento da concha de populações experimentais de Bimphalaria glabrata (Say, 1818) e Helisoma duryi (Wetherby, 1879). Reversamente observou-se que aquele produto mineral bloqueou a oviposição de ambas as espécies, a partir da segunda semana do experimento, quande proporcionado, isoladamente ou associado, a latoso ou a folhas de alface. Em consequiência, supõe-se que sua ampla utilização nas novas áreas de cultivo, obtidas através de métodos modernos de irrigaçăo, poderá, adicionalmente -- ao ser carreado pelas chuvas, para ecossistemas lênticos ou lóticos - reduzir as populações pioneiras de diferentes espécies de Bimphalaria constituindo-se útil meio de controle da esquistossomose mansoni, em zonas rurais. Ademais, poderá ser eficaz no controle dos hospedeiros intermediários de Schistosoma mansoni que, usualmente, se estabelecem em lagoas de criação de peixes - cuja multiplicação, em áreas tropicais, vem sendo incentivada, quer como atividade econômica alternativa para o pequeno proprietário rural quer como exigência de necessidade nutricional das comunidades humanas mais pobres. Supõe-se, ainda, que o material testado poderá controlar populações de limneídeos, hospedeiros intermediários de Fasciola hepatica. São sugeridos testes de campo que possam efetivamente comprovar a hipótese levantada, e também estudos destinados ao conhecimento do mecanismo de açâo do elemento magnésio no bloqueio da fertilidade de moluscos. Salienta-se a necessidade de pesquisas especiais sobre o efeito de diferentes concentrações de magnésio em ovos e formas juvenís de planorbideos, bem como sobre miracidios e cercárias (intra-caramujos e livre-natantes) de trematódeos. controle.

UNITERMOS: Esquistossomose mansônica, controle. Planorbídeos,

* Trabalho complementado con auxílio financeiro do CNPq - Projeto PDE/10-02-1.

** Do Laboratório de Ecologia do Centro de Pesquisas "René Rachou"/FIOCRUz - Caixa Postal 1743 - 30000 - Belo Horizonte, MG - Brasil; da Universidade Federal de Minas Gerais - Belo Horizonte, MG.

*** Da Universidade Católica de Minas Gerais - 30000 - Belo Horizonte, MG (estudante de Biologia) 
MILWARD-DE-ANDRADE, R. \& TORGA, L. F. Ação inibidora de termofosfato magnesiano sobre a fecundidade de planorbídeos e seu possivel significado no controle da esquistossomose mansoni. Rev. Saúde públ., S. Paulo, 15:59-71, 1981.

\section{N TRODUCA O}

Sob a denominação genérica de termofosfato magnesiano, é comercializado um produto mineral de uso na correção da acidez e na carência tradicional en fósforo dos latossolos (Defelipo e col.: 1978).

O adubo en questão é, industrialmente. obtido pelo processo de desfluorização pelo calor. Assim, o fosfato natural - enriquecido com silica e magnésio (dolomita) -é derretido em forno elétrico, à temperatura de $1.500{ }^{\circ} \mathrm{C}$, e, após, submetido a choque térmico com jato d’água, secado e moido.

O produto final é um pó inódoro, cinza, incapaz de absorver umidade atmosférica. Contém $18 \%$ de $\mathrm{P}_{2} \mathrm{O}_{5}, 28 \%$ CaO, $16,5 \%$ de $\mathrm{MgO}$ e traços de $\mathrm{Co}, \mathrm{Cu}, \mathrm{Mn}, \mathrm{Mo}, \mathrm{Fe}$ e $\mathrm{SiO}_{2}$. E insolúvel na água, apresentando quimicamente $\mathrm{pH}$ de 8,0 a 8,5 - porém, fisicamente neutro.

Segundo, ainda, a empresa que o industrializa, torna-se solúvel quando em contato con os ácidos fracos do solo e das raízes das plantas. De seu fósforo, $16,5 \%$ é dito como solúvel em ácido cítrico a $2 \%$ (1:100).

Con vistas à utilizaçào de substâncias mais apropriadas à criação econômica de planorbídeos, en laboratório - sobretudo, sem o inconveniente usual de individuos portadores de conchas frágeis e quebradiças - procedeu-se a testes preliminares com o produto em consideração; todavia, sem perder de vista a possobilidade de se obter resultado diverso do originalmente procurado - face a conhecimento disponivel na literatura especializada e orientado, principalmente, no sentido de esclarecer condições ecológicas nas quais usualmente se desenvolvem as populaçoes naturais de planorbídeos (Sioli 22.24, 1951, 1953, 1956; Deschiens ${ }^{3}, 1954$; Milward-de-Andrade 12.14, 1954, 1959; Milward-de-Andrade $e$ col.15.16, 1955, 1957; Harrison e col. ", 1966; Williams ${ }^{33}, 1970$; Thomas e col.:- 28. 29, 1974, 1975; Nduku e Hartison ${ }^{17}$, 1976;
Pointier e col. ${ }^{19}, 1977$; Leveque e col. ${ }^{\circ}$ 1978).

A resposta preliminar obtida - e diversa daquela inicialmente procurada - constituiu ponto de partida para a proposição do que os autores supoem poder ser un novo e talvez útil método de controle de populaçóes naturais dos hospedeiros intermediários de Schistosoma mansoni (Samhon, 1907) e, também, de limneideos: hospedeiros intermediários de Fasciola hepatica Linnaeus, 1758.

Os resultados obtidos são aqui relatados, seguindo-se as ilações que eles sugerem, como anteriormente resumido (Milward-de-Andrade ${ }^{11}, 1980$ ).

\section{MATERIAL E MÉTODOS}

O experimento foi desenvolvido ao longo de cinco semanas: iniciando-se às $16 \mathrm{~h}$ de 2 de outubro e terminando às $16,20 \mathrm{~h}$ de 6 de novembro de 1979.

1. Seleção prévia dos planorbideos Todos os exemplares utilizados foram previamente selecionados entre individuos que, comprovadamente, desovavan com regularidade.

Assim, en copos de vidro, com $100 \mathrm{ml}$ de água de torneira, desclorada, foranı distribuidos exemplares, isolados, de ambas espécies utilizadas: Biomphalaria glabrata (Say, 1818) e Helisoma duryi (Wetherby, 1879), alimentados diariamente com fragmentos de alface: Lactuca sativa $\mathrm{L}$.

Ao final de cinco dias $(24$ a 28 de setembro de 1979) procedeu-se à seleção daqueles individuos submetidos ao experimento proposto. Entre os 20 B.glabrata, inicialmente utilizados, registrou-se 110 desovas e 1427 ovos. Ou 71,4 ovos/caramujo ou, ainda, 5,5 desovas/caramujo. E, entre os $20 \mathrm{H}$.duryi, detectou-se 43 desovas $e$ 857 ovos. Ou 42,9 ovos/caramujo ou, ainda, 2,2 desovas/caramujo. 
MILWARD-DE-ANDRADE, R. \& TORGA, L. F. Ação inibidora de termofosfato magnesiano sobre a fecundidade de planorbideos e seu possivel significado no controle da esquistossomose mansoni. Rev. Saude públ., S. Paulo, 15:59-71 1981.

Os 19 espécimens férteis, restantes, de cada espécie nomeada, foram transferidos para duas cubas plásticas, e ai mantidos como eventuais substitutos dos que morressem ao longo do experimento. Mas, de qualquer modo, lançando-se mão, sempre, de indivíduos de talhe análogo ao dos mortos.

A seleção prévia mencionada justificou-se como precaução ante o fato, não infreqüente, de prolongada supressão de oviposição entre moluscos planorbideos (ditada por motivos que ainda carecen de explicação), particularmente, Helisoma duryi (Roney ${ }^{20}$, 1943; Milward-de-Andrade ${ }^{13}$, 1980).

2. Planorbideos utilizados - Os 20 exemplares iniciais de $B$.glabrata eram pigmentados e tinham, todos eles, $12 \mathrm{~mm}$ de diâmetro das conchas. Seus ascendentes foram, anteriormente, capturados no Lago da Pampulha, Belo Horizonte, MG. Os 20 exemplares de $H$. duryi eram albinos, também mediam $12 \mathrm{~mm}$ e descendiam de espécimens recém-introduzidos, da Região Neártica (América do Norte), no Estado de Goiás (Paraense 18, 1976).

3. Agua e recipientes - A água utilizada era de torneira, porém, desclorada com solução de $\mathrm{Na}_{2} \mathrm{~S}_{2} \mathrm{O}_{3} .5 \mathrm{H}_{2} \mathrm{O}$ p.a. Semanalmente, quantidades iguais a $1.800 \mathrm{ml}$ eram colocadas em cada uma das oito cubas plásticas: $20 \times 30 \times 10 \mathrm{~cm}$, utilizadas como aquários. Ocorreu, pois, renovação periódica da massa líquida. As cubas eram mantidas fechadas com tampas, brancas e opacas, do mesmo material plástico.

4. Temperatura $\left({ }^{\circ} \mathrm{C}\right)-$ Ademais do registro regular das máximas e mínimas do ar, anotou-se diariamente - de uma única cuba, tomada como padrão - entre $16 \mathrm{e}$ $17 \mathrm{~h}$, a temperatura da água $\mathrm{e}$, também, a do ambiente.

5. Alimento - Estava constituido por fragmentos de folhas frescas de Lactuca sativa e, também, do próprio adubo testado.
A alface foi diariamente renovada. Porém, o adubo - na quantidade de $100 \mathrm{ml}$ (quando isolado ou associado à alface) oul na de $50 \mathrm{ml}$ (quando associado a igual proporção de latossolo) - foi semanalmente substituido.

Para cada cuba utilizada: 1-4 (com bionfalária) e 5-8 (com helisoma), que abrigava sempre cinco exemplares de planorbídeos, tivemos, em termos de alimento, o que se segue:

a) Con Biomphalaria glabrata Cuba-1: apenas alface; cuba-2: alface + adubo; cuba-3: apenas adubo; cuba-4: adubo + latossolo.

b) Com Helisoma duryi - Cuba-5: apenas alface; cuba-6: alface + adubo; cuba-7: apenas adubo; cuba-8: adubo + latossolo.

O latossolo foi obtido de formigutiro estando, pois, constituido de material proveniente do horizonte pedológico "B"; portanto, jsento de contaminantes orgânicos comuns ao horizonte "A", Antes de utilizado, foi manual e vigorosamente mesclado ao termosfato magnesiano.

Em cada cuba foi mantido, à superfícic d'água, um pequeno retângulo de polietireno (isopor), branco, rugoso, con 6 a 8 $\mathrm{cm}$, para suporte adicional das desovas dos moluscos.

6. Dados registrados - Em relação a cada uma das oito cubas então mencionadas, foram anotados os seguintes dados: a) $\mathrm{pH}$ da água "nova" e da "velha", determinado através de peagômetro; b) temperatura $\left({ }^{\circ} \mathrm{C}\right)$, da água $\mathrm{e}$ do ar; c) mortalidade diária, substituindo-se os caramujos por outros do mesmo porte, pré-selecionados e mantidos nas duas cubas ditas "de reserva"; d) número de desovas; $e$ ) número de ovos e de ovos/ desova; $f$ ) diâmetro final de cada exemplar utilizado, ou seja, crescimento de ambas as espécies em consideração. 
MILWARD-DE-ANDRADE, R. \& TORGA, L. F. Ação inibidora de termofosfato magnesiano sobre a fecundidade de planorbídeos e seu possivel significado no controle da esquistossomose mansoni. Rev. Saúde puibl., S. Paulo, 15:59-71, 1981.

\section{RESULTADOS}

Temperaturas $(\circ \mathrm{C})$.

As minimas e máximas do ar, diariamente registradas, oscilaram entre os seguintes valores extremos: $21,5^{\circ}$ e $285^{\circ} \mathrm{C}$, respectivamente.

As amostras de água "novas" tiveram como valores médios semanais: $25,5^{\circ}$ ( 1 \% semana), $25,5^{\circ}\left(2^{a}\right), 23,5^{\circ}\left(3^{a}\right), 26,5^{\circ}$ (4a) (. $25,5^{\circ} \mathrm{C}\left(5^{\mathrm{a}}\right)$.

Cunsiderando todas as anotações diárias, a temperatura média das águas "novas" foi de $25,3^{\circ}$; das "velhas", $25,9^{\circ} \mathrm{C}$. Ocorrendo, pois, variação média de apenas $0,6^{\circ} \mathrm{C}$.

$p H$

Os seus valores, para cada cuba, foram determinados duas vezes por semana: ou seja, das águas "novas" (após introduzidas nas cubas, que continham alimento) e das águas "velhas" (uma semana depois de abrigarem os planorbídeos, alimentos $e$ dejeções.

No caso das cubas com B.glabrata, o pH médio das águas "novas" oscilou de 6,78 a 7,78; o das "velhas", de 6,52 a 7,58. Registrou-se, portanto, diferença para menos, entre os valores iniciais e os finais.
Ou seja, $6,78: 6,52=0,26 ;$ e $7,78: 7,58=$ 0,20 .

Para as quatro cubas com $H$. duryi, foram anotados, respectivamente, os valores médios de 6,74 (minimo) a 7,94 (máximo), para as águas "novas"; e 6,50 (mínimo) a 7,70 (máximo), para as águas "velhas", semanalmente.

As diferenças foram, portanto, análogas às anteriormente nomeadas: 0,24 , em ambos os casos.

\section{Mortalidade.}

Ao término das cinco semanas do experimento, haviam sido substituidos $65 \%$ (13) dos exemplares de $B$. glabrata inicialmente utilizados.

Daquele total, 11 (55\%) encontravam-se em contacto com o termofosfato magnesiano testado (cubas 2, 3 e 4).

No caso de $H$. duryi, o total de substituições não ultrapassou a $4(20 \%)$ espécimens; porém, $1(5 \%)$ deles pertencia à população alimentada exclusivamente com alface (cuba-5).

Os dados que se seguem esclarecem a marcha dos acontecimentos registrados: substituições, por cuba, em função do tempo de observaçōes (5 semanas):

a) B. glabrata

$$
\begin{aligned}
& \text { CUBA } \\
& 1 \text { (alface }) \\
& 2(+ \text { adubo }) \\
& 3(\text { adubo }) \\
& 4(+ \text { latossolo })
\end{aligned}
$$

Total

$\begin{array}{rrrrrc}1 a & 2 a & 3 a & 4 a & 5 a & \text { Total } \\ 0 & 0 & 2 & 0 & 0 & 2 \\ 0 & 0 & 2 & 2 & 0 & 4 \\ 0 & 0 & 0 & 2 & 1 & 3 \\ 0 & 0 & 0 & 1 & 3 & 4 \\ - & -- & - & - & - & - \\ 0 & 0 & 4 & 5 & 4 & 13\end{array}$

b) H. duryi

$$
\begin{aligned}
& 5 \text { (alface }) \\
& 6(+ \text { adubo }) \\
& 7 \text { (adubo }) \\
& 8(+ \text { latossolo })
\end{aligned}
$$

$\begin{array}{rr}0 & 0 \\ 0 & 0 \\ 0 & 0 \\ 0 & 0 \\ - & - \\ 0 & 0\end{array}$

$\begin{array}{rrrr}0 & 1 & 0 & 1 \\ 0 & 0 & 0 & 0 \\ 1 & 0 & 0 & 1 \\ 1 & 0 & 1 & 2 \\ - & - & - & - \\ 2 & 1 & 1 & 4\end{array}$


MILWARD-DE-ANDRADE. R. \& TORGA. L. F. Ação inibidora de termofosfato magnesiano sobre a fecundidade de planorbideos e seu possivel significado no controle da esqulstossomose mansonl. Rev. Saude públ., S. Paulo, 15:59-71, 1981.

Observa-se, pois, que nas duas primeiras semanas não foi registrada mortalidade de planorbídeos. $E$, nas três primeiras, não pereceu também nenhuma bionfalária alimentada apenas com adubo (cuba-3) ou com este produto associado a latossolo (cuba-4). Também não morreu nenhum dos helisomas alimentados com alface + adubo (cuba-6).

Crescimento dos planorbideos.

Entre bionfalárias, apenas $2(15,4 \%)$ dos 13 individuos substituidos conservavam 0 mesmo diămetro inicial: $12 \mathrm{~mm}$. Os outros 11 mostraram variações: $13-16 \mathrm{~mm}$.

Quanto à helisoma, 2 (50\%) conservaram o mesmo talhe: $12 \mathrm{~mm}$; os outros $2(50 \%)$ substituidos tinham $14 \mathrm{~mm}$ de diâmetro.

Os diâmetros $(\mathrm{mm})$ dos planorbideos substituídos, segundo as cubas nas quais se encontravam e as ocasiōes (semanas) mencionadas, eram os seguintes:

a) B. glabrata

$\begin{array}{cccccc}\text { CUBA } & 3 ! & 4 ! & 5 ! & \text { Total } \\ 1 & 12,15 & - & - & 2 \\ 2 & 12,14 & 14,16 & - & 4 \\ 3 & - & 13,15 & 14 & 3 \\ 4 & - & 15 & 13,14,15 & 4 \\ & & & & -\end{array}$

b) $H$. duryi

$\begin{array}{lllll}5 & - & 14 & - & 1 \\ 6 & - & - & - & 0 \\ 7 & 12 & - & - & 1 \\ 8 & 12 & - & 14 & 2 \\ \text { Totais } & 2 & 1 & 1 & 4\end{array}$

Tem-se, pois, que a taxa de crescimento não se mostrou proporcionalmente maior com o avançar do tempo. Pois, p. ex., na cuba-3 os dois mortos (4a semana) tinham 13 e $15 \mathrm{~mm}$, respectivamente; e o que pereceu

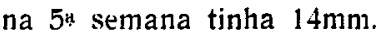

Considerando os 20 exemplares de cada espécie nomeada, vivos no último dia do experimento, verificou-se que 0 diâmetro médio de cada população de cinco exemplares (cubas 1-4 e 5-8) - vale dizer, de acordo com o alimento proporcionado - era da seguinte grandeza:

$\begin{array}{cccc}\text { CUBA } & \text { B. glabrata } & \text { CUBA } & H . \text { duryi } \\ 1 & 14,2 & 5 & 13,4 \\ 2 & 14,8 & 6 & 12,8 \\ 3 & 13,8 & 7 & 12,8 \\ 4 & 15,2 & 8 & 12,75\end{array}$


MILWARD-DE-ANDRADE, R. \& TORGA, L. F Ação inibidora de termofosfato magnesiano sobre a fecundidade de planorbídeos e seu possivel significado no controle da esquistossomose mansoni. Rev. Saúde públ., S. Paulo, 15:59-71, 1981.

Chama atenção o fato de as populações de bionfalária terem aumentado o diâmetro de 1,8 a $3,2 \mathrm{~mm}$, enquanto as de helisoma cresceram de 0,75 a $1,4 \mathrm{~mm}$. Talvez se explique pela circunstância de, normalmente, as conchas de helisomas serem mais altas e robustas que as de bionfalárias.

Relacionando-se, por outro lado, o ganho em diâmetro com o alimento proporcionado, pode-se verificar que, em todos os casos, as populações foram beneficiadas.

Para bionfalária, o aumento médio variou de $1,8 \mathrm{~mm}$ (cuba-3: apenas adubo) a $3,2 \mathrm{~mm}$ (cuba-4: adubo + latossolo). Nessa última cuba detectou-se o maior dos exemplares: $19 \mathrm{~mm}$; os outros quatro indivíduos mediam 13 (1), 14 (1) e $15 \mathrm{~mm}$ (2), respectivamente.

Os diàmetros das bionfalárias variaram de 12 a $16 \mathrm{~mm}$ (cuba-1); 12 a $17 \mathrm{~mm}$ (cuba-2) e 12 a 15 (cuba-3).

Entre os helisomas, os individuos que mais cresceram contavam apenas com fragmentos frescos de alface (cuba-5). $\mathrm{E}$ os que tiveram menor ganho médio dispunham de adubo associado a latossolo (cuba-8).

Igual aumento médio $(0,8 \mathrm{~mm})$ foi registrado entre os indivíduos que dispunham de apenas termofosfato magnesiano (cuba-7) ou deste produto associado à alface (cuba-6).

\section{Desovas e ovos depositados.}

$\mathrm{Na}$ análise dos dados obtidos (Tabelas 1 e 2), deve-se ter presente o fato das substituições dos individuos que morreram no decurso do experimento.

A Tabela 1 registra o número de desovas e ovos, ao longo das cinco semanas e segundo o tipo de alimento proporcionado. É de se observar a redução progressiva da oviposição quando $B$. glabrata contava com alface + adubo: $308(35,7 \%)$ ovos na $1^{\text {in }}$ semana e $86(10 \%)$ na $5^{\text {a }}$ e última semanas (cuba-2).
Diferença significativa pode, também, ser observada comparando-se o controle (cuba-1) com os mencionados dados da cuba-2 (alface + adubo). No primeiro caso, tem-se $101(71,6 \%)$ desovas e $2.082(70,7 \%)$ ovos; no segundo, $40(28,4 \%)$ e 862 $(29,3 \%)$, respectivamente.

$\mathrm{Na}$ ausência de alimento verde (alface) a interrupção da oviposição processou-se mais vigorosamente. Assim, nas cubas 3 e 4 foram registradas apenas $5,2 \%$ (8) e 3,9\% (6) desovas; ou $4 \%$ (129) e $3,9 \%$ (126) ovos, respectivamente. $E$ todos eles quase exclusivamente na primeira semana do experimento.

Saliente-se que as populações das cubas 1 e 2 permaneceram estáveis nas duas primeiras semanas; o mesmo ocorrendo com as das cubas 3 e 4 , nas três primeiras semanas do experimento. Isto é, durante o tempo mencionado não houve substituições ou morte de exemplares.

Os dados registrados para $H$. duryi assemelham-se aos de $B$. glabrata. Podendo-se, entretanto, supor que helisoma seria talvez um pouco mais sensivel ao termofosfato que bionfalária (Tabela $1, b$ ).

Comparativamente, a população-controle de $B$. glabrata (cuba-1) mostrou-se mais prolífera que sua análoga de $H$. duryi (cuba-5). De fato, no primeiro caso, anotou-se $101(51,3 \%)$ desovas e 2.082 $(56,9 \%)$ ovos; no segundo, $96(48,7 \%)$ e $1.574(43,1 \%)$, respectivamente.

Diferença, porém, mais significativa pode-se verificar comparando as populações das cubas 2 e 6 : ambas com alface + adubo. Ou seja, $40(65,6 \%)$ e $21(34,4 \%)$ desovas, e $862(70,9 \%)$ e $354(29,1 \%)$ ovos, respectivamente, para bionfalária e helisoma.

\section{Desovas/caramujo e Ovos/caramujo.}

Os parâmetros mencionados salientam melhor os resultados $e$ as diferenças de fecundidade, segundo os alimentos proporcionados. 
MILWARD-DE-ANDRADE, R. \& TORGA, L. F. Açăo inibidora de termofosfato magnesiano sobre a fecundidade de planorbideos e seu possivel significado no controle da esquistossomose mansoni. Rev. Saride pübl., S. Paulo, 15:59-71, 1981.

Assim, B. glabrata liberou 21 desovas/ caramujo quando utilizou exclusivamente alface (cuba-1). Porém, quando este alimento encontrava-se associado à termofosfato magnesiano, ovipôs apenas 8 desovas/caramujo. Naquelas condições, 0 número de ovos/caramujo decresceu de 416,4 para 172,4. Os demais dados, como também para $H$. duryi, podem ser apreciados a seguir: a) B. glabrata

Cuba Desovas/caramujo Ovos/caramujo

$$
1
$$

2

$$
21,0
$$

416,4

172,4

3

8,0

25,8

4

1,6

25,2

b) $H$. duryi

$\begin{array}{rrr}5 & 19,2 & 314,8 \\ 6 & 4,2 & 70,8 \\ 7 & 1,0 & 14,0 \\ 8 & 1,0 & 7,6\end{array}$

T A B E L A 1

Desovas e ovos depositados por $B$. glabrata e $H$. duryi, segundo o tipo de alimento disponivel, em laboratório. đurante cinco semanas. Belo Horizonte, 2/outubro a 6/novembro/1979.

\begin{tabular}{|c|c|c|c|c|c|}
\hline \multirow[b]{2}{*}{ Semana } & & \multicolumn{4}{|c|}{ Desovas: Ovos, segundo o alimento } \\
\hline & & $\begin{array}{l}\text { Alface } \\
(C-1)\end{array}$ & $\begin{array}{c}\text { Alface }+ \\
\text { Adubo } \\
(C-2)\end{array}$ & $\begin{array}{l}\text { Adubo } \\
(C-3)\end{array}$ & $\begin{array}{c}\text { Adubo }+ \\
\text { Latossolo } \\
\quad(C-4)\end{array}$ \\
\hline 1 & & $14: 261$ & $13: 308$ & $7: 104$ & $6: 126$ \\
\hline 2 & & $27: 525$ & $6: 138$ & 0: 0 & 0: 0 \\
\hline 3 & & $27: 636$ & $6: 122$ & $0: 0$ & $0: 0$ \\
\hline 4 & & $9: 198$ & $11: 172$ & $0: 0$ & $0: 0$ \\
\hline 5 & & $24: 462$ & 4: 86 & 1: 25 & $0: 0$ \\
\hline \multirow[t]{2}{*}{ Totais: } & No & $101: 2082$ & $40: 862$ & $8: 129$ & $6: 126$ \\
\hline & $\%$ & $65,2: 65,1$ & $25,8: 26,9$ & $5,2: 4,0$ & $3,9: 3,9$ \\
\hline
\end{tabular}

a) B. glabrata

\begin{tabular}{|c|c|c|c|c|c|}
\hline & & $(C-5)$ & $(C-6)$ & $(C-\gamma)$ & $(C-8)$ \\
\hline \multicolumn{2}{|l|}{1} & $19: 381$ & $10: 196$ & $4: 50$ & $2: 20$ \\
\hline \multicolumn{2}{|l|}{2} & $22: 375$ & 5: 91 & $0: 0$ & 1: 5 \\
\hline \multicolumn{2}{|l|}{3} & $19: 331$ & 2: 9 & $1: 20$ & $1: 3$ \\
\hline \multicolumn{2}{|l|}{4} & $20: 272$ & 2: 30 & $0: 0$ & $0: 0$ \\
\hline \multicolumn{2}{|l|}{5} & $16: 215$ & 2: 28 & $0: 0$ & $1: 10$ \\
\hline \multirow[t]{2}{*}{ Totais: } & No & $96: 1574$ & $21: 354$ & $5: 70$ & $5: 38$ \\
\hline & $\%$ & $75,6: 77,3$ & $16,5: 17,4$ & $3,9: 3,4$ & $3,9: 1,9$ \\
\hline
\end{tabular}

b) H. duryı

Nota: Os números entre parênteses referem-se às cubas utilizadas, 
MILWARD-DE-ANDRADE, R. \& TORGA, L. F. Açăo inibidora de termofosfato magnesiano sobre a fecundidade de planorbideos e seu possivel significado no controle da esquistossomose mansoni. Rev. Saúde públ., S. Paulo, 15:59-71, 1981.

\section{T A B E L A 2}

Desovas e ovos depositados por B. globrata e $H$. duryi, durante cinco semanas, em laboratório, segundo o tipo de alimento proporcionado. Belo Horizonte, $2 /$ outubro a $6 /$ novembro/1979.

a) B. glabrata

\begin{tabular}{|c|c|c|c|c|}
\hline \multirow{3}{*}{ Alimento } & \multicolumn{4}{|c|}{ Oviposições } \\
\hline & \multicolumn{2}{|c|}{ Desoras } & \multicolumn{2}{|c|}{ Ovos } \\
\hline & No & $\%$ & $\mathrm{No}$ & $\%$ \\
\hline Alface & 101 & 65,1 & 2.082 & 65,2 \\
\hline Alface + Adubo & 40 & 25,8 & 862 & 26,9 \\
\hline Adubo & 8 & $\mathbf{5 , 2}$ & 129 & 4,0 \\
\hline Adubo + Latossolo & 6 & 3,9 & 126 & 3,9 \\
\hline Totais & 155 & 100,0 & 3.199 & 100,0 \\
\hline
\end{tabular}

b) H. duryi

\begin{tabular}{|c|c|c|c|c|}
\hline Alface & 96 & 75,5 & 1.574 & 77,3 \\
\hline Alface + Adubo & 21 & 16,5 & 354 & 17,1 \\
\hline Adubo & 5 & 3,9 & 70 & 3,4 \\
\hline Adubo + Latossolo & 5 & 3,9 & 38 & 1,9 \\
\hline Totais & 127 & 100,0 & 2.036 & 100,0 \\
\hline
\end{tabular}

c) B. glabrata

\begin{tabular}{|c|c|c|c|c|c|}
\hline Alface & & 101 & 71,6 & 2.082 & 70,7 \\
\hline Alface + Adubo & & 40 & 28,4 & 862 & 29,3 \\
\hline & Totais & 141 & 100,0 & 2.944 & 100,0 \\
\hline
\end{tabular}

d) H. duryi

\begin{tabular}{|c|c|c|c|c|c|}
\hline Alface & & 96 & 82,1 & 1.574 & 81,6 \\
\hline Alface + Adubo & & 21 & 17,9 & 354 & 18,4 \\
\hline & Totais & 117 & 100,0 & 1.928 & 100,0 \\
\hline
\end{tabular}

Observa-se, pois, que o termofosfato magnesiano exerceu ação bloqueadora da ovogênese de ambas as espécies em consideração.

Sem embargo, o adubo mostrou-se aparentemente capaz de alimentar regularmente e, também, promover o crescimento das conchas daqueles moluscos.

Ademais, não foi possivel atribuir ao pro- duto mineral testado qualquer responsabjlidade pelas taxas de mortalidade registradas no decurso do experimento relatado.

Por outro lado, considerando a técnica de processamento industrial do adubo (sujeição à temperatura de $1.500^{\circ} \mathrm{C}$ ) admite-se, em princípio, afastada interferência de contaminante, como eventual ou suposto agente do bloqueio nomeado. 
MILWARD-DE-ANDRADE, R. \& TORGA, L, F. Ação inibidora de termofosfato magnesiano sobre a fecindidade de planorbideos e seu possivel significado no controle da esquistossomose mansoni. Rer. Saúde públ., S. Paulo, 15:59-71. 1981.

\section{DISCUSÃO E CONCLUSŌES}

A ilação possivel, com vistas à utilizaçào prática do conhecimento aqui relatado, deve ser precedida de considerações relacionadas, em primeiro termo, ao ambiente físico ou habitat dos planorbideos e, em segundo, a importância ou significado do elemento magnésio para o ser vivo. Ressaltando-se, finalmente, as circunstâncias nas quais o adubo magnesiano poderá, secundária ou adicionalmente, concorrer para o controle da esquistossomose e, eventualmente, da fasciolose.

Qualidade e concentração dos numerosos elementos dissolvidos nas águas naturais correlacionam-se, fundamentalmente, às características geofísicas e climatológicas do meio. Assim, a biocenose de qualquer ecossistema aquático estará, sempre e necessariamente, vinculada às propriedades físico-quimicas da massa liquida que, em último termo, regulará a qualidade, a densidade e a periodicidade dos organismos - sem embargo da importância dos fatores intrin$\operatorname{secos}$ que regulam a estrutura e 0 funcionamento das diferentes comunidades.

Em sentido amplo, porém, a natureza pedológica do substrato não parece influir na distribuição dos planorbídeos (Deschiens ", 1954). Salvo, entretanto, quando o tipo dos sedimentos implica alteraçóes ou pobreza de sais inorgânicos dissolvidos na água, como demonstrou Sioli,2:.23.26 1951, 1953, 1956) em estudos pioneitos realizados na Região Amazônica.

Dessa forma, a presença e a densidade das pupulações de planorbídeos numa área ou região maior dependerão da natureza química da água dos biótopos e, em particular, do balanço das concentraçijes dos diferentes ions disponiveis - cuja incorporaçāo pode ocorrer somente nas partes moles do molusco (p. ex., $\mathrm{P}, \mathrm{K}, \mathrm{Ti}, \mathrm{Cr}$, $\mathrm{Co}, \mathrm{Ni}$ e $\mathrm{Ba}$ ) ou, simultaneamente, nelas $\mathrm{e}$ nas conchas (p. ex., Na, Mg, Al, Si, Ca, V, $\mathrm{Mn}, \mathrm{Fe}, \mathrm{Cu}$ e $\mathrm{Sr}$ ), como revelado por aná- lise espectrográfica (Milward-de-Andrade e Paulini 15, 1957).

Com efeito, iá foram também demonstradas maior freqüència de ocorrência e densidades mais altas de $B$. glabrata em águas de maior dureza total, segundo faixa de variação de 6,0 a $260,0 \mathrm{ppm} \mathrm{CaCO}_{3}$; porém, simultaneamente, com dureza magnésica inferior a $50,0 \mathrm{ppm} \mathrm{CaCO}_{3}$, em mais de 92\% das determinações (Milward-de-Andrade,12.14 1954, 1959; Milward-de-Andrade e col 1s, 1955).

En verdade, na forma de bicarbonato, $u$ teor de magnésio é usualmente pequeno nas águas doces, malgrado $\mathrm{Mg}$ constitua cerca de $2,1 \%$ da crosta terrestre - como, p. ex., magnesita $\left(\mathrm{MgCO}_{3}\right)$ e dolomita $\left(\mathrm{MgCO}_{3}\right.$. $\mathrm{CaCO}_{3}$ ), com $28,7 \%$ e $13,8 \%$, respectivamente, de magnésio.

A espécie $B$. glabrata já foi assinalada em biótopos naturais com até $510 \mathrm{mg} / 1 \mathrm{de}$ $\mathrm{MgCl}_{2}$. A letalidade manifesta-se a $2 \mathrm{~g} / 1$ (Deschiens ${ }^{3}, 1954$ ), reduzindo-se a oviposição com 410 a $763 \mathrm{mg} / 1$ de $\mathrm{MgCl}_{2}$ (Leveque e col.s, 1978).

Para B. pfeifferi, espécie africana, foi demonstrado que uma relação $\mathrm{Mg} / \mathrm{Ca}$ elevada $(12,4)$ tem efeito inibidor sobre a fecundidade, que é totalmente bloqueada, em laboratório, ao atingir 19.7 (Harrison e col. ${ }^{\circ}$, 1966).

Porém, segundo Leveque e col. ${ }^{6}$, " $B$. glabatra suporte d'autant mieux les fortes teneurs en Magnesium que le rapport $\mathrm{Mg}$ / $\mathrm{Ca}$ est faible. L'effet inhibiteur n'apparait qu'à une valeur de ce rapport d'environ 30 . Ce chiffre est beaucoup plus élevé que celui constanté pour $B$. pfeifferi $(12,4)$ et souligne bien la plus grande plasticité physiologique de B. glabrata".

Se é verdade, pois, que o elemento magnésio bloqueia a fecundidade de moluscos planorbideos, ignora-se, por outra parte, o mecanismo de sua ação.

Sabe-se de longa data que o magnésio é o segundo cationte mais abundante nos 
MILWARD-DE-ANDRADE, R. \& TORGA, L. F Ação inibidora de termofosfato magnesiano sobre a fecundidade de planorbideos e seu possível significado no controle da esquistossomose mansoni. Rev. Saúde puibl., S. Paulo, 15:59-71. 1981.

liquidos celulares. Sua essencialidade às várias etapas enzimáticas do metabolismo de carboidratos é reconhecida, sendo sua carência acompanhada por perturbaçōes estruturais e funcionais em diferentes animais: ratos, carneiros, bois, entre outras (Goodman e Gilman ${ }^{4}$, 1973).

Sua redução no serum provoca, experimentalmente, hiperemia, irritabilidade neuromuscular progressiva e tetania, reversivel com a administração do cationte (Warren e col. ${ }^{31}, 1968$ ).

A ocorrência de $M g$ na matéria viva só pode ser bem compreendida quando relacionado aos elementos $\mathrm{Na}, \mathrm{K}$ e $\mathrm{Ca}$.

A hipermagnesemia redunda na depressão do sistema nervoso central e da união neuromuscular periférica, no homem (Del-Castillo Eugbaek 2, 1954). O animal anestesiado pelo $\mathrm{Mg}$ volta normalmente à consciência alguns segundos após a administração venosa de Ca. Porém, segundo autores, não há explicação aceitável para a narcose pelo $\mathrm{Mg}$ e para o antagonismo do Ca. A intoxicação por $M g$ é rara, caracterizando-se por queda abrupta da pressão arterial e pela paralisia respiratória (Shils 21, 1969; Maclntyre 10, 1963).

O elemento é importante constituinte do esqueleto de equinodermas e crustáceos. Naqueles animais e em moluscos a concentração do cationte $M g$ é muito variável: o fluído extracelular aproxima-se da composição do meio externo. Wacker e Vallee : (1958) observam que $\mathrm{Mg}$ deve influir em quase todos os processos vitais, assinalando que fosfatases e pirofosfatases alcalinas são ativadas, e também fosfatase do ácido prostático; sendo ele imprescindivel onde quer que difosfotiamina seja necessária.

O magnésio é essencial à molécula de clorofila, na qual teria papel similar ao do ferro na hemoglobina. $O$ adulto médio (70 kg) tem cerca de $2.000 \mathrm{mEq}$ de $\mathrm{Mg}$, 60.000 de $\mathrm{Ca}$, mais de 5.500 de $\mathrm{Na}$ e $3.000 \mathrm{mEq}$ de $\mathrm{K}$ (Widdowson e col. ${ }^{3}$, 1951). O sangue total contém 2-4 mg/100 $\mathrm{ml}(1,7-3,4 \mathrm{mEq} / 1) ; \mathrm{e}$, nos músculos $(21 \mathrm{mg} / 100 \mathrm{~g})$, supõe-se que o magnésio funcione como ativador de muitas enzimas do sistema glicolítico, no metabolismo dos carboidratos (Harper, 5 1973).

Várias oleoginosas, soja e alimentos do mar são ricos em $\mathrm{Mg}$ : 100 a $400 \mathrm{mg} / 100 \mathrm{~g}$; também grãos integrais, ervilhas e feijōes crus e secos: 100 a $200 \mathrm{mg}$ de $\mathrm{Mg} / 100 \mathrm{~g}$ (McCance e Widdowson", 1960).

$\mathrm{Na}$ agricultura, óxido e sufato de magnésio são crescentemente utilizados - corrigindo a acidez e fertilizando solos deficientes para o cultivo de batatas e frutos citricos, principalmente.

Nos dias atuais, no Brasil, esforços sāo postos na ampliação de cultivares, ganhos através de modernos projetos de irrigação: vales dos rios São Francisco, Jequitinhonha, entre outros. Vem sendo incentivada, sobretudo, a piscicultura intensiva como atividade econômica alternativa e, também, para atender inquestionáveis deficiências nutricionais dos camponeses: Nordeste e Sudeste, em particular.

Pois bem, em ambos os casos: canais de irrigação e lagoas de piscicultura, o alı mento das massas líquidas estimulam 0 aumento das áreas de transmissão da esquistossomose mansoni — sem que atençāo adequada e estudos aconselháveis sejam, direta ou indiretamente, diligenciados pelas agências financiadoras, nacionais e internacionais (Banco Mundial, Banco Interamericano de Desenvolvimento, entre outros), de tais projetos

De fato, aquelas massas hidricas retidas: ou de escoamento moroso: lagos artificiais, canais de irrigação, lagoas de criação de peixes e açudes, despontam às centenas como ecossistemas apropriados à colonização pioneira de planorbídeos, hospedeiros intermediários de Schistosoma mansoni.

Em outros termos, a já precária situação sanitária do camponês tende a se agravar, enquanto àqueles projetos - necessários, 
MILWARD-DE-ANDRADE, R. \& TORGA, L. F. Açăo inibidora de termofosfato magnesiano sobre a fecundidade de planorbideos e seu possivel significado no controle da esquistossomose mansoni. Rev. Saúde públ., S. Paulo, 15:59-71, 1981.

por certo - não forem incorporadas indispensáveis medidas de caráter profilático.

Os novos cultivares ou áreas irrigadas reclamarão, por certo, corretivos e adubos. As lagoas e açudes de piscicultura carecerão de águas mais eutróficas, férteis em plâncton: organismos indispensáveis à alimentação de certas espécies indispensáveis à fauna ictíica terminal (carnivoros).

$\mathrm{Da}$ questão assim posta, crê-se, a utilização ampla e necessária de termofosfato magnesiano atenderia, de um lado, o objetivo primário, i.e., adubação dos novos cultivares. De outro, ao ser arrastado pelas chuvas, o fertilizante propiciará aumento da produtividade primária dos ecossistemas aquáticos: favorecendo, consequentemente, a piscicultura. E, por fim, adicionalmente, o corretivo magnesiano se constituirá em barreira ou fator de controle das populações naturais de bionfalárias e de limneídeos consequentemente, da esquistossomose e da fasciolose.

Valerá, pois, investigar. Testar a hipótese que se estriba, fundamentalmente, na atividade anti-conceptiva do termofosfato magnesiano, específica em relação aos moluscos nomeados.

Supōe-se, ainda, que resultados particularmente efetivos seriam alcançados em focos isolados ou em massas de água que se dispõem em acidentes geográficos especiais: ilhas, por exemplo.

Necessário será também verificar a eventual capacidade de bloqueio do $\mathrm{Mg}$ quando utilizado sobre ovos e formas evolutivas juvenís de planorbídeos, e sua persistência ao longo do tempo. E sua ação sobre o trematódeo intra-caramujo, e sobre cercárias e miracidios livrenatantes.

Obviamente, os estudos aí não se esgotariam. Valendo lembrar, p. ex., que recentemente foi detectada lisozima (mucopeptideo $\mathrm{N}$-acetilmuramilidrolase EC 3.2.1.17) na glândula digestiva e em extratos cefalopediais de $B$. glabrata, cuja atividade pode ser inibida por $\mathrm{MgCl}_{2}, \mathrm{CaCl}_{2}$ ou por altas (25 $\mathrm{mM}$ ) concentraçōes de $\mathrm{NaCl}, \mathrm{KCl}$ e $\mathrm{LiCl}$, enquanto baixas concentrações (5 $\mathrm{mM}$ ) aumentam a atividade da enzima (Kassim e Richards 7, 1978).

Indagações em outros campos poderão ser formuladas. Por exemplo, em relação a outros componentes da biocenose aquática como um todo. Os mais importantes representantes do necton: os peixes, mereceriam atenção especial face $o$ aumento das concentrações de $\mathrm{Mg}$ dissolvidas na água e a quantidade do cátion eventualmente retida ou acumulada pelo animal. 
MILWARD-DE-ANDRADE, R. \& TORGA, L. F. Açăo inibidora de termofosfato magnesiano sobre a fecundidade de planorbideos e seu possivel significado no controle da esquistossomose mansoni. Rev. Saúde públ., S. Paulo, 15:59-71. 1981.

MILWARD-DE-ANDRADE, R. \& TORGA, L. F. [The inhibiting action of magnesium thermophosphate on the fecundity of planorbids and the possible significance of this in controlling Schistosoma mansoni] Rev. Saúde públ., S. Paulo, 15:59-71, 1981.

ABSTRACT: The efficacy of magnesium thermophosphate (a soil corrective and fertilizer) was tested as food for laboratory planorbids for a period of five weeks, during which time the shell growth of Biomphalaria glabrata (Say, 1818) and Helisoma duryi (Wetherby, 1879) experimental populations was observed. Surprisingly, this mineral product blocked the oviposition of both species from the second week on, when added to the latosoil either isolatedly or associatedly. Consequently, magnesium phosphate, when widely used in new agricultural areas obtained through modern irrigation methods, may be carried to lentic and lotic ecosystems by rain and reduce the pioneer populations of different Biomphalaria species, thus constituting a useful means of Schistosomiasis mansoni control in rural areas. Moreover, it may also be effective in the control of the Schistosoma mansoni intermediate hosts that usually live in fish-breading ponds whose increase in number is often encouraged as an alternative economic activity for the small rural owner or as a means for meeting nutritional requirements. This material may also control limnaeid populations, which are Fasciola hepatica intermediate hosts. Specific field tests that may actually demonstrate these hypotheses, as well as studies aiming to find out how the magnesium element blocks the mollusks' fertility, are suggested. The need for further research on the action on the eggs and young forms of planorbides and on miracidia cercariae (free and intra-snail) of trematodes, of different magnesium concentrations is pointed out.

UNITERMS: Schistosoma mansoni, control. Planorbidae.

\section{REFER ENCIAS BIBLIOGRAFICAS}

1. DEFELIPO, B, $\mathrm{V}$, et al. Adubos fosfatados na correção da acidez do solo. Seiva, Viçosa, MG, 38(86): 41-50, 1978

2. DEL-CASTIllo, J. \& ENGBAEK, L. Nature of neuromuscular block produced by magnesium. $J$. Physiol., London, 124 : 370-84, 1954.

3. DESCHIENS, R. Incidence de la minérallsation de l'eau sur les mollusques vecteurs des bilharzioses: consequences pratiques. Bull. Soc. Path. exot., 47: 915-29, 1954.

4. GOODMAN, L. S. \& GILMAN, A. As bases farmacológicas da terapentica. Rio de Janeiro, Ed. Guanabara Koogan, 1973.

5. HARPER, H. A. Manual de quimica fisiológica. São Paulo, Atheneu, 1973.
6. HARRISON, A. D. et al. The effect of a high magnesium to calcitm ratio on the egg-laying rate of an aquatic planorbid snail, Biomphalaria pfeifferi. Ann. trop. Med. Parasit., 60:212-4, 1966.

7. KASSIN, O. O. \& RICHARDS, C. $\mathrm{s}$. Biomphalaria glabrata: Lysozyme activities in the hemolymph, digestiv gland and headfoot of the intermediate host of Schistosoma mansoni. Exp. Parasit., 46: 218-24, 1978.

8. LEVEQUE, $C$. et al. Influence de quelque facteurs du milieu sur la fécondité de Biomphalaria glabrata (Say, 1818) (Mollusca, Planorbidae) dans les conditions du laboratoire. Ann. Parasit., Paris, 53: 393-402, 1978. 
MILWARD-DE-ANDRADE, R. \& TORGA, L. F. Ação inibidora de termofosfato magnesiano sobre a fecundidade de planorbideos e seu possível significado no controle da esquistossomose mansoni, Rev. Saüde públ., S. Paulo, 15:59-71. 1981.

9. MCCANCE, R. A. \& WIDDOWSON, E. M. The composition food. London, Her Magesty's Stationary Office, 1960. (Great Britain Med. Res. Council Sp. Rep. Ser).

10. MacINTYRE, I. An outline of magnesium metabolism in health and disease. A review. J. chron. Dis., 16: 201-15, 1963.

11. MILWARD-DE-ANDRADE, R. Ação inibidora do adubo "Yoorin" sobre a fecundidade de Biomphataria glabrata e Helisoma duryi. (Mollusca, Planorbidae). In: Congresso Brasileiro de Parasitologia, 5\%, Rio de Janeiro, 1980. Resumos. Rio de Janeiro, 1980. p. 158.

12. MILWARD-DE-ANDRADE, R. Alguns dados hidroquímicos de criadouros de planorbideos no Distrito Federal. Rev. bras. Malar., 6:573-5, 1954.

13. MILWARD-DE-ANDRADE, R, Comportamento de Helisoma duryi (Wetherby, 1879) submetidos à inédia. (Mollusca, Planorbidae). Rev. bras. Biol., 1980. [no prelo]

14. MILWARD-DE-ANDRADE, R. Ecologia Rev. bras, Malar, 11: 171-217, 1959.

15. MILWARD-DE-ANDRADE, R. \& PAULIN 1 E. Nota sobre a composiçāo elementar de Australorbis glabratus (Say, 1818). coletados em Belo Horizonte e Neves, Estado de Minas Gerais, Brasil. Rev. bras. Malar., 9: 559-63, 1957.

16. MILWARD-DE-ANDRADE, R. et al. Contribuição para o conhecimento dos criadouros de planorbideos, na área do Distrito Federal. I - Variação de diferentes fatores químicos de suas águas. Rev. bras. Malar., 7: 103-30, 1955.

17. NDUKU, W. K. \& HARRISON, A. D. Calcium as limiting factor in the biology of Biomphalaria pfeifferi (Krauss). Ann. trop. Med. Parasit., 49: 143-70, 1976.

18. PARAENSE, W. L. A natural population of Helisoma auryi in Brazil. Malacologia, 15: $369-76,1976$

19. POINTIER, J. P. et al. Principaux facteurs régissant la densité des populations de Biomphalaria glabrata (Say, 1818), mol. lusque vecteur de la schistosomose en Guadeloupe (Antilles francaises). Ann. Parasit. hum. comp., 52: 277-323, 1977.

20. RONEY, H. B. The effect of temperature and light on oxygen consumption and rate of development of Helisoma. Ecology, 24: 218-43, 1943.

21. SHILS, M. E. Experimental human magnesium depletion. Medicine, Baltimore, 48: 61-85. 1969.
22. SIOLI, H. Alguns resultados e problemas da limnologia amazônica. Bol. tecn. Inst. Agron. Norte, 24: 3-44, 1951.

23. SIOLI, H. Estudo preliminar das relações entre a geologia e a limnologia da zona Bragantina (Pará). Bol, tecn. Inst. Agron. Norte, 24: 67-76, 1951.

24. SIOLI, H. The only focus of endemic bilharziosis (Schistosoma mansoni) ir: the Amazon Region: observation on the ecology of the vector Tropicorbis (Obstrutio) paparyensis F'. Baker and their practical importance. Geneva, World Health Organization, 1956. (WHO/Biol. Ecol./1).

25. SIOLI, H. Schistosomiasis and limnology in the Amazon Region. Amer. J. trop. Med. Hyg., 2: 700-7, 1953.

26. SIOLI, H. Sobre a sedimentação na várzea do baixo Amazonas. Bol. tecn. Inst. Agron. Norte, 24: 45-65, 1951.

27. THOMAS, J. D. \& LOUGH, A. The effect of external calcium concentration on the rate of this ion by Biomphataria glabrata (Say). J. anim. Ecol., 43: 861-71. 1974

28. THOMAS, J. D. et al. The chemical ecology of Biomphalaria glabrata (Say) the snail host of Schistosoma mansoni: the search for factors in media conditioned by snails with their growth and reproduction. $J$. appl. Ecol., 12: 421-36, 1975.

29. THOMAS, J. D. et al. The effects of calclum in the external environment on the growth and natalis rate of Biomphalaria glabrata (Say), J. anim. Ecol., 43: $839-60, \quad 1974$

30. WACKER, W. E. C. \& VALLEE, B. L. Magnesium metabolism. New Engl. J. Med., 259: 431-8, 475-82, 1958.

31. WARREN, E, C. et al, Magnesium metabolism. New Engl. J. Med., 278: 658-63, 712-7, 772-6, 1968.

32. WIdDOWSON, E. M. et al. Chemical composition of human body. Clin. Sci., 10: 113-25, 1951.

33. WILLIAMS, N. V. Studies on aquatic pulmonate snails in Central Africa. 1. Field distribution in relation to water chemistry. Malacologia, 10: 153-64, 1970.

Recebido para publicąão em 17/06/1980 A provado para publicaçāo em 12/09/1980 